\title{
Inovações Didáticas no Ensino de Economia: Experimentos Econômicos, Atividades On-line e Autoavaliação
}

\section{GradP \\ Revista de Graduação USP}

\author{
Roseli da Silva* \\ Departamento de Economia \\ Faculdade de Economia, Administração e Contabilidade de Ribeirão Preto da Universidade de São Paulo
}

* Autor para correspondência: roselisilva@usp.br

\section{RESUMO}

Este artigo apresenta três técnicas didáticas alternativas aos métodos tradicionais de ensino de economia em nível de graduação. Por meio de tais expedientes, tem-se o objetivo de alcançar maior eficiência no processo ensino-aprendizagem e, assim, engajar os estudantes de maneira efetiva e ativa na construção do conhecimento, tanto em termos individuais quanto coletivos.

Palavras-chave: Práticas Didáticas Universitárias; Economia Experimental; Atividade Didática On-lime; Autoavaliação.

\begin{abstract}
This paper presents three alternative teaching techniques to the traditional methods used at the economics undergraduate courses, in order to achieve greater efficiency in the teaching-learning process, engaging students effectively and actively in their own process and in the collective construction of knowledge.
\end{abstract}

Keywords: University Teaching Practices; Experimental Economics; On-line Teaching Activity; Self-assessment.

\section{Introdução}

O ensino de economia em nível de graduação, nas principais universidades do mundo, tem passado por inúmeras críticas, tanto de acadêmicos quanto de estudantes, principalmente após a crise financeira de 2007-2008. Diante disso, promoveram-se revisões curriculares, tanto de estrutura quanto de conteúdo, buscando, principalmente, atualizar o ensino de modo a considerar os avanços da teoria econômica dos últimos trinta anos, em geral ausentes dos livros-textos mais utilizados no mundo ${ }^{1}$. Desenvolver práticas didáticas inovadoras para o ensino de economia à graduação, em favor da construção do conhecimento como um processo coletivo e social, que estejam em consonância com esse movimento internacional, torna-se mais do que uma necessidade, uma urgência.

Neste contexto, insere-se o presente artigo, que tem por objetivo, principalmente, discutir e apresentar três práticas didáticas que venho desenvolvendo ao longo dos últimos cinco anos: os experimentos econômicos, cujo objetivo é propiciar um ambiente de aprendizado em que os conceitos abstratos sejam compreendidos a partir da análise de resultados concretos produzidos pela participação ativa do aluno em um ambiente de simulação que reproduza a realidade (experimento); as atividades didáticas por meio da internet, que pretendem promover uma reflexão crítica sobre o conteúdo técnico das disciplinas ministradas mediante sua conexão com fatos reais e da construção colaborativa do conhecimento; e um mecanismo de incentivo para a autoavaliação e conscientização do aluno sobre os resultados alcançados em uma avaliação dissertativa individual, que tenho denominado de "chute educado".

A Universidade de São Paulo (USP), por meio da Comissão de Apoio Pedagógico (CAP), vinculada à Pró-Reitoria de Graduação, tem buscado responder aos desafios recentes da docência universitária, provendo espaços para formação dos professores em pedagogia e didática e para a dis- 
cussão desses desafios, no âmbito de cada unidade, de acordo com suas respectivas peculiaridades de área científica. $\mathrm{O}$ que há de comum a todas as áreas é o desafio fundamental de incentivar, nos alunos, o desenvolvimento da razão crítica, da capacidade de "aprender a pensar", capacitando-os a buscar soluções criativas e inovadoras para um mundo em constante mudança (LIBÂNEO, 2009).

Em consonância com as ações centrais, a USP de Ribeirão Preto iniciou seu Grupo de Apoio Pedagógico (GAPRP) Interunidades ainda em 2002, formalmente constituído em abril de 2004, e, desde então, vem contribuindo efetivamente para que nós, docentes, possamos melhorar nossas práticas de ensino ao realizar cursos de formação em pedagogia universitária, encontros, seminários e workshops abertos a toda comunidade para a discussão dessa agenda. Em regra, tais iniciativas são guiadas por palestrantes qualificados da própria universidade e por convidados de outras instituições que desenvolvem pesquisas sobre os temas de docência universitária e profissionalização docente. Como representante do Departamento de Economia da FEA-RP desde 2010, é por meio das atividades do GAPRP que tenho encontrado estímulo e formação pedagógica para melhorar meu trabalho como docente dessa instituição, e assim contribuir para buscar as mudanças em nosso papel no processo de ensino-aprendizagem das gerações que já nasceram sob a égide da comunicação em suporte digital e de farta disponibilidade de informação.

Por meio das discussões teóricas e práticas sobre metodologias de ensino e aprendizagem realizadas em encontros abertos e oficinas e no $\mathrm{V}$ Curso Pedagogia Universitária de 2015, oferecido pelo GAPRP, tenho compreendido as referências conceituais e teóricas que embasam práticas até então realizadas por mim instintivamente e por experiência prática (ANASTASIOU \& ALVES, 2004; GATTI, 2003; ZABALZA, 2004). Como resultado de tal processo, nos últimos cinco anos dos meus quase dezesseis de docência universitária, venho aplicando técnicas que considero inovadoras em sala de aula com o objetivo de incentivar o aluno a tomar uma posição ativa em seu processo de aprendizagem, por meio de experimentos econômicos, de atividades on-line via $b l o g$ e de um mecanismo de incentivo à autoavaliação. As metodologias empregadas nesses casos são descritas brevemente a seguir. Além disso, a título de exemplificação, apresento e analiso os resultados de algumas dessas atividades e, por fim, teço algumas considerações finais.

\section{Metodologias Utilizadas e Resultados}

As práticas aqui apresentadas foram aplicadas a nove turmas dos cursos de graduação em Economia (seis), Matemática Aplicada a Negócios (duas) e Economia e Controladoria (uma), em que ministrei as disciplinas de Macroeconomia I (duas turmas), Matemática Aplicada à Economia (duas turmas), Finanças I, Economia Monetária (três turmas) e Econometria, ao longo do primeiro semestre de 2012, e dos anos de 2013 e 2014 . No total, foram mais de 350 alunos matriculados que tiveram a oportunidade de experimentar a aplicação prática de uma ou mais dessas iniciativas.

\section{Experimentos Econômicos}

$\mathrm{O}$ ensino de economia por meio de jogos ou experimentos em sala de aula já tem um longo percurso documentado, advindo dos avanços em economia experimental. Nesse sentido, há vários tipos de experimentos que podem facilmente ser desenvolvidos nas salas de aula que tratam de temas como: decisões individuais, leilões, negociações, teoria dos jogos, estruturas de mercados, alocação de portfólio, moeda e inflação, emprego e produto etc. (BEGKER et al., 2006).

A eficácia dos experimentos como método pedagógico requer que, além da sua simples aplicação, o professor utilize os dados gerados para uma profunda discussão com os alunos. No decorrer do curso, o docente pode recorrer à experiência do jogo para continuar aprofundando outros conceitos, que devem ser deduzidos pelos próprios graduandos por meio da experiência vivida. Ele deve ainda conter-se e ter atenção suficiente com a linguagem utilizada para não influenciar os estudantes, levantando questões capazes de induzir 
o raciocínio deles. Dado seu fim pedagógico, é importante que o experimento ocorra sempre antes da apresentação dos conceitos econômicos, e não depois, e, para sua eficácia, vale a mesma regra fundamental dos experimentos de pesquisa econômica: a existência de incentivos que devem ser desenhados a fim de se estimularem a participação e o interesse dos alunos nos procedimentos e resultados ao longo do experimento.

HOLT \& TANGA (1996) descrevem como projetar e pôr em prática experiências pedagógicas, com apoios simples, sem a necessidade de computadores ou laboratórios próprios para execução de experimentos controlados. Os dois tipos mais populares de experimentos em sala de aula são de mercados competitivos e de teoria dos jogos, mas há uma literatura bastante ampla sobre tais experimentos como instrumento didático [BECKER et al. (2006) apresentam um capítulo sobre o tema].

No presente semestre (2015), para as turmas de Economia Monetária, apliquei o experimento básico de equilíbrio de mercado competitivo (HOLT, 1996), um experimento sobre demanda por moeda frente a cenários de risco (EWING, 2004) e outro que auxiliou os alunos a compreender o complexo conceito de expectativas racionais (HAZLETT, 1996). Seleciono para apresentação aqui o ex- perimento que introduz conceitos referentes ao mercado competitivo devido a sua capacidade de abordar importantes conceitos econômicos (oferta e demanda). Seguindo HOLT (1996), o experimento é desenhado de forma que os estudantes sejam colocados em uma situação que simula o funcionamento de mercados competitivos. Para tanto, separa-se a classe entre compradores e vendedores e usa-se um baralho para distribuir de maneira aleatória valores de custo de produção aos vendedores (cartas de cor preta) e valores que apontam a quantia máxima que cada comprador está disposto a pagar pela mercadoria (cor vermelha). O exercício dura cerca de cinquenta minutos para leitura de instruções e realização de oito a dez rodadas de negociações.

Ao término das rodadas de negociações, inicia-se o período de debates. Um ponto importante na discussão é permitir aos alunos assimilarem a intuição de que o preço de equilíbrio diz respeito a um resultado natural da ação de compradores e vendedores em busca de seu interesse individual ("mão invisível"). Tal fato se consolida a partir da convergência dos preços praticados em torno do valor de equilíbrio, conforme as rodadas são repetidas e as informações são disseminadas, como ilustra a Figura 1.

Desse modo, é muito mais fácil compreender que as teorias do consumidor e da firma em con-

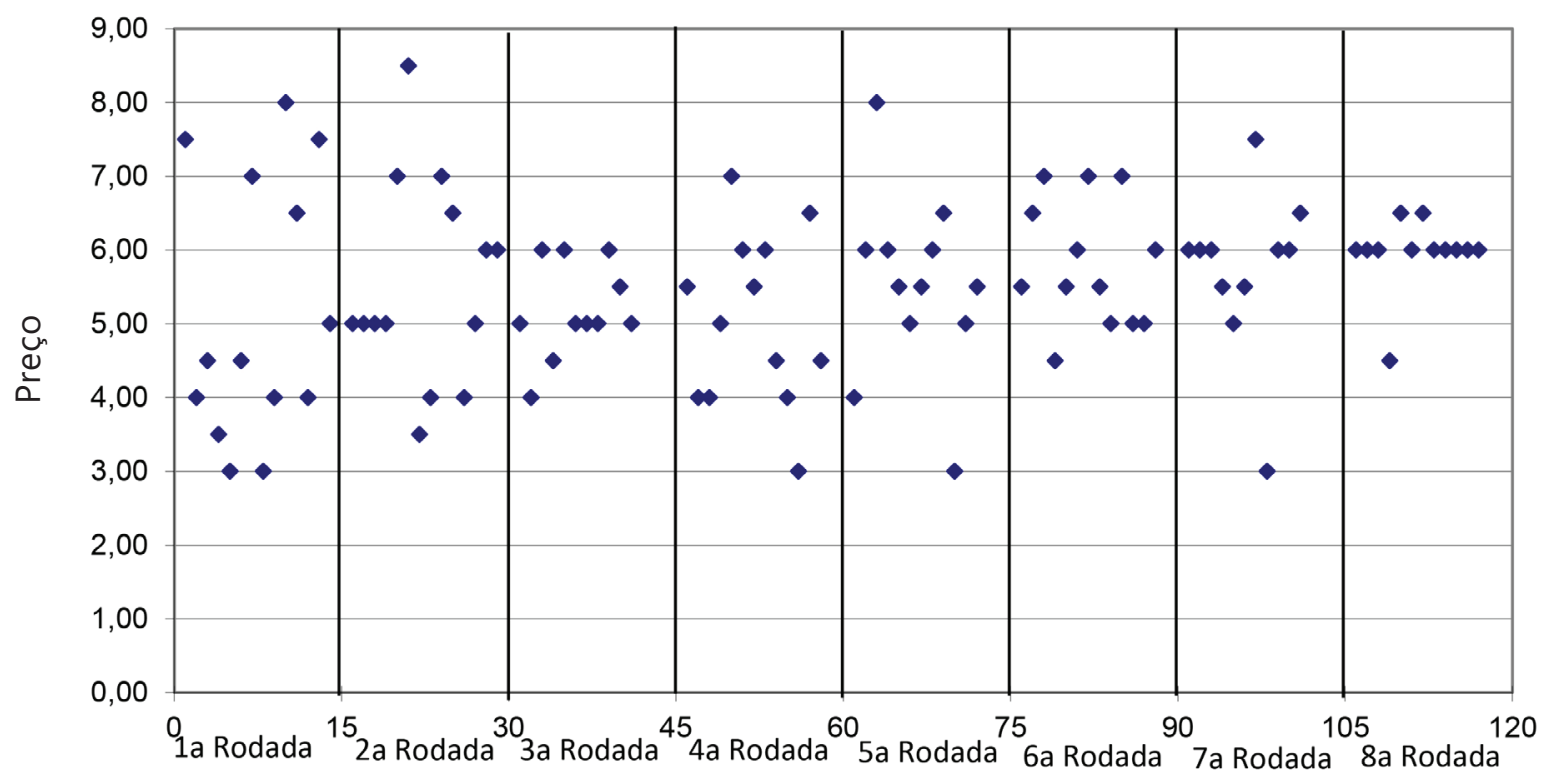

Figura 1 - Resultado típico dos preços negociados no experimento de equilíbrio de mercado competitivo. 
corrência perfeita apenas apresentam de forma simplificada tais comportamentos. Na Figura 2, destaco a estrutura de custos e de disposição a pagar, definidas a priori pelas escolhas das cartas, que apresentam um preço de equilíbrio 6,0 .

Essa técnica de ensino já foi aplicada por mim, em colaboração com uma colega, para o ensino de conceitos básicos de economia para estudantes do ensino médio, com muito sucesso em um projeto de Cultura e Extensão (BATISTA \& SILVA, 2010).

Sobre a eficácia para o processo de aprendizagem desse tipo de inovação didática, que se assemelha às metodologias de aprendizado baseado em problemas, Emerson e Taylor (2004) mostram evidências favoráveis, a partir de uma análise econométrica com grupo de controle que, reforçam minha percepção, após aplicar diversos experimentos em disciplinas teóricas de economia, de que há ao menos um ponto muito positivo em tal prática: a aproximação entre professor e aluno, propiciando um ambiente social adequado para o desenvolvimento do processo de ensino-aprendizagem.

\section{Atividade Didática On-line}

Preparar atividades que utilizem um ambiente natural para a geração digital é fundamental para despertar o interesse e a participação dos estudantes. O uso de tecnologia computacional, para além do e-mail e sites de internet, ainda é escasso entre professores de economia, e poucos se valem de atividades mais complexas realizadas por meio do computador ou de inovações didáticas como técnicas de aprendizado ativo, em geral, porque tais atividades impõem um elevado custo pessoal para o próprio professor.

No entanto, esse pode ser um meio de o docente estimular discussões sobre temas de estudo, ou, ainda, uma forma de os estudantes entrarem em contato com a diversidade de pontos de vista, o que pode ser usado como uma excelente ferramenta de ensinar a pensar criticamente. Se utilizados sabiamente e com cuidado, os blogs proporcionam vivacidade ao conteúdo das disciplinas de teoria aplicada de uma maneira que poucas tecnologias poderiam fazer.

Para tanto, é essencial que a atividade no blog seja programada e monitorada pelo professor e, mais

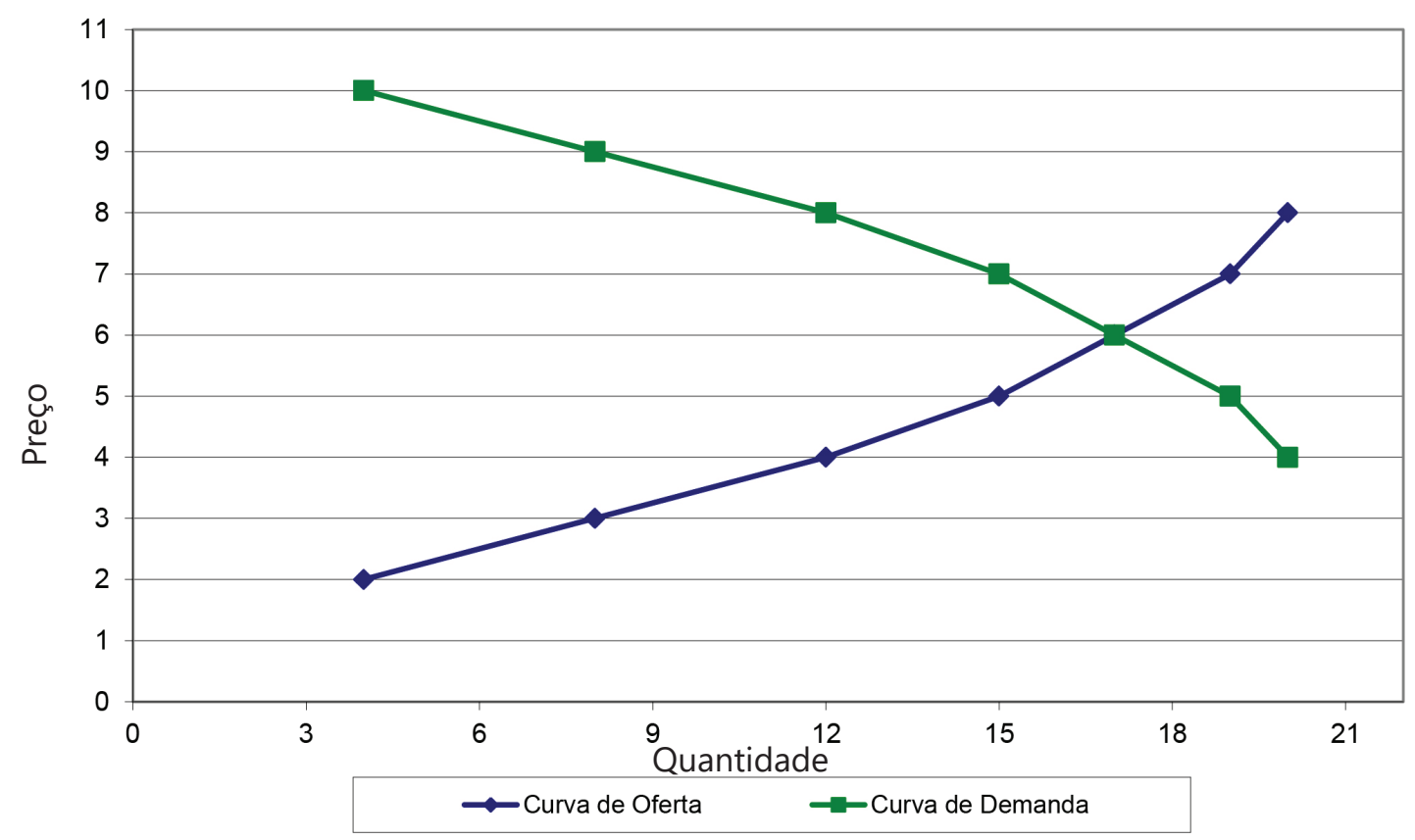

Figura 2 - Custos de produção (oferta) e disposição a pagar (demanda) de acordo com as cartas definidas para serem sorteadas entre ofertantes e compradores. 
importante, que as dúvidas, opiniões e sugestões recolhidas por meio de tal iniciativa sejam levadas de volta para a sala de aula. Esse procedimento contribui para o dinamismo, propicia a integração entre os colegas e o estreitamento da relação professor-aluno, elemento essencial para o aprendizado.

Assim como qualquer atividade didática, é necessário que haja incentivos eficientes, que, como sempre, traduzem-se em avaliação das atividades em uma nota que deve compor a média final dos estudantes.

Desenvolvo atividades didáticas em disciplinas na área de Economia Monetária e de Macroeconomia, por meio do meu blog denominado Random Walk, $<$ http://roselisilva.wordpress.com/>. Tais atividades consistem em trabalhos realizados em grupos. Cada um desses, por meio de sorteio inicial, torna-se responsável por pesquisar sobre um tema previamente definido e produzir um texto, com conteúdo conceitual/teórico e não normativo, sobre o assunto, citando fontes e links para as notícias pesquisadas. $\mathrm{O}$ texto deve buscar uma linguagem informal que possa elucidar conceitos econômicos para um público amplo e conter no máximo quatro mil caracteres com espaço. Além disso, cada estudante comenta e debate o texto/tema, indicando outras notícias relacionadas, e/ou ajudando a melhorar a explicação econômica do fenômeno. Realizada pela professora, a avaliação da atividade é dividida em 50\% para a qualidade do texto e $50 \%$ pela participação individual ao longo do semestre, acompanhada e contabilizada pelo assistente, normalmente um monitor ou estudante de mestrado, como parte de seu programa de formação docente.

Os resultados têm sido satisfatórios tanto pela qualidade dos textos produzidos quanto pela participação dos alunos mediante comentários e trocas de informações. Em linha gerais, tal engajamento discente pode ser detectado em mais de 70\% dos estudantes de cada turma. Desse modo, convém ainda assinalar que a atividade também contribui para a integração da turma, bem como para a construção de uma relação entre professor-aluno mais efetiva, uma vez que discussões on-line eram trazidas para o âmbito da sala de aula e usadas como motivador para a introdução/compreensão de conceitos e teorias do conteúdo do curso.

\section{Autoavaliação ou "Chute Educado"}

A presente atividade tem como objetivo conscientizar o estudante de seu próprio desempenho em provas dissertativas individuais, contribuindo para que ele se torne ativo no processo de aprendizagem e crítico em relação a seus métodos de estudo e de preparação para um tipo de avaliação como este que, em geral, compõe no mínimo 70\% da média final nas disciplinas que ministro.

Para colocar em prática a atividade, é necessário que o professor reserve, em seu cronograma de aulas, datas para a realização de vistas de provas, como é natural em processos de avaliação formativa. No dia agendado, antes de entregar as provas corrigidas, discutir as respostas esperadas e tirar dúvidas sobre o conteúdo, o docente propõe aos estudantes que respondam ao que chamo de "chute educado", que diz respeito à seguinte pesquisa:

Essa técnica corresponde a uma aplicação do conceito de expectativas racionais em sala de aula e foi elaborada com base em BLACKWELL (2010).

\section{Pesquisa Experimental}

Pense sobre sua preparação para a prova desta disciplina e, baseado em sua experiência de estudo ao longo de sua vida, responda às duas questões abaixo. Recompensa: se você acertar a sua nota num intervalo de 0,5 ponto para cima ou para baixo, receberá como recompensa 0,5 na nota da prova em questão. Exemplo: você disse que sua nota esperada é 7,0, se sua nota efetiva estiver entre 6,5 e 7,5 ela será acrescida de meio ponto.

1) Quantas horas, aproximadamente, você estima que estudou para esta prova?

Resposta: horas no total.

2) Que nota você acredita ter alcançado na prova?

Resposta: (número entre 0 e 10, com até 2 casas decimais)

Nome: 
Espera-se que o estudante se conscientize do trabalho que realizou, do quanto se dedicou para os estudos do conteúdo e como isso, naturalmente, reflete-se na nota que ele tirou na prova em questão. Esse meio ponto também tem um papel de minimizar distorções que a subjetividade da correção imprime às notas, por mais que adotemos estratégias para evitar tais desvios.

Obviamente, há vários efeitos endógenos nos resultados observados, tais como a reputação do professor (se o professor tem fama de rigoroso, a nota chutada refletirá também essa informação); o grau de dificuldade relativo da disciplina; se o aluno está habituado ou não a refletir sobre seu desempenho em outras disciplinas, com outros professores, entre outros aspectos.

Ao longo dos três últimos anos, venho sistematicamente aplicando esta técnica nas disciplinas que ministro, e pretendo ter, em breve, um banco de dados que permita uma análise econométrica robusta às endogeneidades a fim de analisar os resultados adequadamente. Por enquanto, apresento apenas uma análise exploratória inicial, que permite algumas reflexões interessantes.

Do total de sete turmas em cinco disciplinas diferentes e de 265 alunos matriculados, quase $70 \%$ participa desse levantamento em pelo menos uma das duas provas regulares por semestre. A tabela 1, abaixo, sintetiza as informações e apresenta um teste de diferença de médias para distribuições com variâncias distintas entre a média da nota obtida e a média do chute educado.

A partir desse quadro, observamos que as disciplinas da área de métodos quantitativos parecem demandar maior dedicação de tempo de estudo, considerando que há, em geral, sete semanas de aula e preparação para cada uma das duas provas. Nesse caso o comportamento dos estudantes indica uma hora de estudo por dia útil da semana, o que é bastante razoável em termos de alocação de tempo. Ainda convém assinalar que os testes de diferença de médias, para um nível de significância de 5\%, não rejeitam as hipóteses nulas de igualdade entre as médias para o total da amostra, e para cada uma das disciplinas individualmente (todos os p-valores são superiores a 5\%), sendo que apenas para a disciplina de Matemática Aplicada o teste é limítrofe. Concluímos, portanto, que, em média, os alunos acertam suas notas e estão conscientes de seu desempenho em prova.

Para uma melhor compreensão dos resultados, convém que sejam analisados os comportamentos de acertos e erros do chute educado por classes de notas. Os histogramas da Figura 3 mostram uma distribuição assimétrica tanto de notas quanto de acertos e erros entre alunos de desempenho pior e melhor, justificando um percentual de acertos de 39\% frente aso resultados anteriores para as médias.

No primeiro dos histogramas, observamos que uma parte dos alunos que obtêm notas mais baixas, entre 0 e 2 , chutam notas um pouco mais elevadas,

\begin{tabular}{|c|c|c|c|c|c|c|}
\hline & $\begin{array}{c}\text { Percentual } \\
\text { Total }\end{array}$ & $\begin{array}{c}\text { Média de } \\
\text { Horas de } \\
\text { Estudo }\end{array}$ & $\begin{array}{c}\text { Média } \\
\text { Horas de } \\
\text { Estudo por } \\
\text { Semana }\end{array}$ & $\begin{array}{c}\text { Média } \\
\text { da Nota } \\
\text { Obtida }\end{array}$ & $\begin{array}{c}\text { Média } \\
\text { da Nota } \\
\text { Estimada }\end{array}$ & $\begin{array}{c}\text { Teste de } \\
\text { Diferença } \\
\text { de Médias } \\
\text { (p-valor) }\end{array}$ \\
\hline Total = 370 & $100 \%$ & 32 & 4,6 & 3,60 & 3,48 & $36,5 \%$ \\
\hline Macroeconomia I & $20 \%$ & 20 & 2,9 & 3,58 & 3,79 & $47,6 \%$ \\
\hline Matemática Aplicada & $43 \%$ & 39 & 5,5 & 3,60 & 3,28 & $5,7 \%$ \\
\hline Finanças I & $15 \%$ & 26 & 3,7 & 2,84 & 2,84 & $99,5 \%$ \\
\hline Economia Monetária & $5 \%$ & 20 & 2,8 & 3,88 & 4,14 & $47,5 \%$ \\
\hline Econometria II & $18 \%$ & 37 & 5,3 & 4,15 & 3,79 & $59,9 \%$ \\
\hline
\end{tabular}

Tabela 1 - Síntese do banco de dados e teste de diferença de médias. 


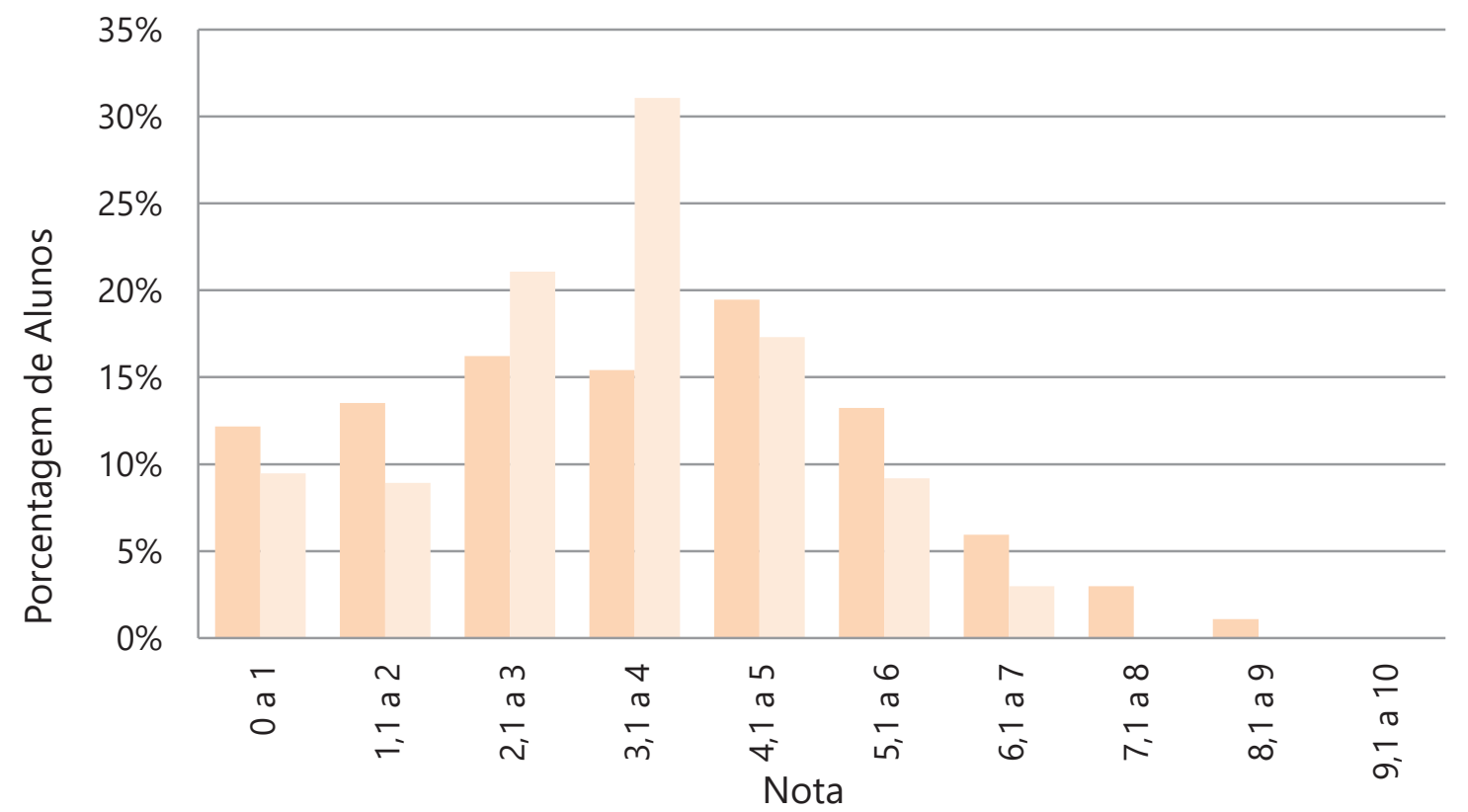

Nota Obtida Chute Educado

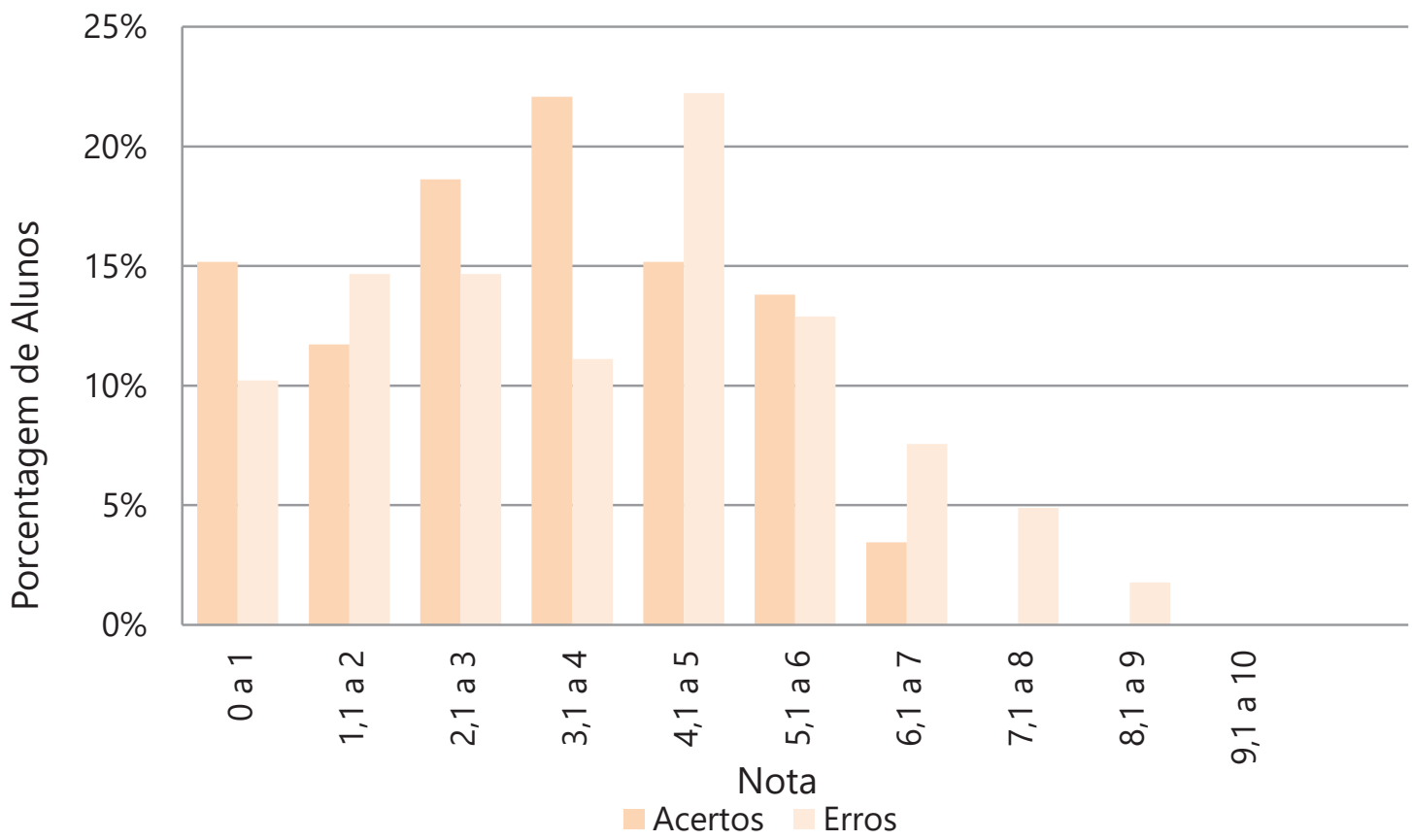

Figura 3 - Histogramas das notas, chutes acertos e erros dentro do limite de 0,5 ponto considerados. À esquerda, histograma de número de alunos por nota obtida e chute educado, e à direita, histograma de número de alunos que acertaram ou erraram o seu chute por faixa de nota obtida.

pois nas classes de 2,1 a 4 há um comportamento no sentido oposto, com uma maior concentração de chutes que de nota efetivas. Por outro lado, o comportamento se inverte entre os alunos que obtêm notas melhores: acima de 4,1 as notas estimadas ficam abaixo das observadas, inclusive não havendo chutes corretos entre os alunos que obtiveram notas acima de 7,1. Já no segundo histograma, o resultado mais interessante encontra-se no fato de que os alunos com notas mais baixas, de 0 a 4 , apresentam o maior percentual de acerto do chute, $68 \%$, enquanto nessa mesma faixa, o percentual de erros é de $51 \%$. Em contrapartida, para aqueles com nota maior que 4,1 , a taxa de acertos cai para 32\%, enquanto a de erros sobe para $49 \%$.

\section{Considerações Finais}

$\mathrm{O}$ aperfeiçoamento das práticas de ensino requer dedicação e esforços intelectuais dos docentes que, sem dúvida, implicam um trade-off 
entre as atividades de ensino e pesquisa, já que o tempo é limitado. Todavia, também é inegável que há uma complementariedade entre a pesquisa e a qualidade da docência, até mesmo em nível de graduação: o professor que ensina em sua área de pesquisa tem melhores condições de contextualizar histórica e teoricamente os conceitos e noções do conteúdo programático, além de apresentar aos alunos as perspectivas de desenvolvimento futuro para área. Tal aspecto tem um potencial de motivação enorme, principalmente para os estudantes que pretendem seguir carreira acadêmica [BECKER (2000) e BOWMAKER (2011) discutem essa complementariedade para a área de economia].

Até que ponto se dedicar a busca de inovação em suas práticas didáticas é, assim, um dilema para todos nós, docentes universitários? Essa é uma questão mais institucional do que pessoal, e cabe a cada universidade sinalizar, com ações concretas e mecanismos de incentivos, a relevância do ensino de graduação em seu papel social. Respondendo a esses estímulos, busco desenvolver práticas e produzir resultados que possam servir para diminuir custos de entrada para outros colegas que queiram aderir à inovação de suas próprias práticas, a exemplo das apresentadas neste artigo.

\section{Notas}

1. O "think tank" constituído a partir de 2009, denominado Institute for New Economic Thinking, que congrega pesquisadores das Universidades de Cambridge, Oxford, Columbia, UCLA, New York University, apenas para citar algumas, desenvolve o Projeto CORE (Curriculum in Open-access Resources in Economics, <http://www.core-econ. org/>), dirigido pela Professora Wendy Carlin da University College London. Estudantes, por sua vez, organizam-se por meio da rede Rethinking Economics (<http://www.rethinkeconomics.org/>).

\section{Referências Bibliográficas}

ANASTASIOU, Léa das Graças Camargos \& ALVES, Lenoir Pessate. "Estratégias de Ensinagem". In: ANASTASIOU, Léa das Graças Camargos \& ALVES, Lenoir Pessate (orgs.). Processos de Ensinagem na Universidade. Pressupostos para as Estratégias de
Trabalho em Aula. Joinville, SC: Univille, 2004, pp. 67-100.

BATISTA, Natália Nunes Ferreira \& SILVA, Roseli da. "Experimentos Econômicos para Estudantes do Ensino Médio da Rede Pública de Ribeirão Preto/SP". Revista de Cultura e Extensão, São Paulo, Universidade de São Paulo, vol. 4, 2010, pp. 45-56.

BEGKER, William E. "Teaching Economics in the 21st Gentury". The fournal of Economic Perspectives. vol. 14, n. 1, 2000, pp. 109-119.

BEGKER, WilliamE.; WATTS, Michael;BEGKER, Suzanne R. (eds.). Teaching Economics: More Alternatives to Chalk and Talk. Cheltenham, UK; Northampton, MA, EUA: Edward Elgar Publishing, 2006.

BLACKWELL, Calvin. "Rational Expectations in the Classroom: A Learning Activity". Fournal for Economic Educators, vol. 10, n. 2, 2010, pp. 1-6.

BOWMAKER, Simon W. The Heart of Teaching Economics: Lessons from Leading Minds. Cheltenham,UK: Edward Elgar Publishing, 2011.

EMERSON, Tisha L. \& TAYLOR, B. "Comparing Student Achievement Across Experimental and Lecture-oriented Sections of a Principles of Microeconomics Course". Southern Economic Fournal, vol. 70, n. 3, 2004, pp. 672-693.

EWING, Bradley T.; KRUSE, J. B.; THOMPSON, M. A. "Money, Demand and Risk: A Classroom Experiment". The fournal of Economic Education, vol. 35, n. 3, 2004, pp. 243-250.

GATTI, Bernardete. "O Professor e a Avaliação em Sala de Aula". Estudos em Avaliação Educacional, São Paulo, Fundação Carlos Chagas, n. 27, jan.jun. 2003, pp. 97-114.

HAZLETT, Denise. "The Lucas Island Experiment". Classroom Expernomics, vol. 5, n. 2, (outono) 1996.

HOLT, Charles A. "Classroom Games: Trading in a Pit Market". Fournal of Economic Perspectives, vol. 10, n. 1, (inverno) 1996, pp. 193-203.

HOLT, Charles A. \& TANGA, M. "Experimental Economics in the Classroom". In: WALSTAD, William. B; SAUNDERS, Phillip. (eds.) Teaching Undergraduate Economics. Boston: Irwin/McGraw-Hill, 1998, pp. 257-268.

SILVA, Roseli \& BATISTA-FERREIRA, N. N. "Resenha Bibliográfica de BECKER, William E.; WATTS, Michael; BECKER, Suzanne R. (eds.). Teaching Economics: More Alternatives to Chalk and Talk. Cheltenham,UK; Northampton, MA, EUA: Edward Elgar Publishing, 2006. 225 p.”. Estudos Econômicos, São Paulo, Universidade de São Paulo, vol. 40, pp. 967-973, 2010.

ZABALZA, Miguel A. O Ensino Universitário: Seu Cenário e seus Protagonistas. trad. Ernani Rosa. Porto Alegre: Artemed, 2004.

Publicado em 05/07/2016. 